\title{
TEMPERATURE EFFECT ON THE PHYSICAL PROPERTIES OF ENAMEL PAINT LAYER ON CEMENT PLASTER
}

\author{
Samiul Kaiser*1 and Mohammad Salim Kaiser ${ }^{2}$ \\ ${ }^{1}$ Department of Civil Engineering \\ ${ }^{2}$ Directorate of Advisory, Extension and Research Services \\ Bangladesh University of Engineering and Technology, Dhaka-1000, Bangladesh
}

Received: 07 May 2019

Accepted: 14 March 2021

\begin{abstract}
The heating effect on the stability and visual colour of enamel paint on cement plaster is evaluated through light intensity ratio of three primary colours (RGB). The painted cement plaster is isochronally heated in an electric resistance furnace at different temperatures for one hour. The investigation of optical images reveals that the original colour of the paint layer on the plaster samples remains more or less unchanged up to heating at $100^{\circ} \mathrm{C}$. However, thermal degradation of the samples becomes evident in colour when they are heated beyond $200^{\circ} \mathrm{C}$ and at $350^{\circ} \mathrm{C}$ the colour becomes already burned. The microstructural images of the samples at room temperature show fine and uniform grains. But at higher heating condition the microstructure of the colour sample is characterized by coarsening grain. The colour of the heated samples are then studied through tristimulus colour ' $L$ *', ' $a$ *' ' $b$ ' ' and ' $E^{*}$ ' values which were analyzed and evaluated in MATLAB software. The results show that after $200^{\circ} \mathrm{C}$ the hunter ' $L^{*}$ ' value starts to decrease greatly up to $250^{\circ} \mathrm{C}$. The hunter ' ${ }^{*}$ ' value shows an increasing trend up to $100^{\circ} \mathrm{C}$ and then begins to decrease until $200^{\circ} \mathrm{C}$. After $200^{\circ} \mathrm{C}$ the same increasing character is showed till $300^{\circ} \mathrm{C}$. The change of hunter ' $b$ ' value remains insignificant up to $100^{\circ} \mathrm{C}$ and shows decreasing trend between $100^{\circ} \mathrm{C}-250^{\circ} \mathrm{C}$ range and an increase after $250^{\circ} \mathrm{C}$ up to $300^{\circ} \mathrm{C}$. It is graphically shown that the proportion of all three colours decreases with the increasing temparature. The overall change of colour ' $E$ ' occurs with increasing heating temperature due to moisture releasing, chemical changes and thermal degradation simulteneously. The thickness of enamel paint layer comply the above degradation by showing the nature of decresing trend.
\end{abstract}

Keywords: Enamel paint; Cement plaster; Thermal degradation; Tristimulus values; Microstructure.

\section{INTRODUCTION}

Enamel paint is a kind of paint that air-dries to a hard, usually glossy finish, used for coating surfaces that are outdoors or otherwise subject to hard wear or variations in temperature (Lambourne and Strivens, 1999; Piper, 1965). For its availability, easy application, high durability and wide range of colour variations, enamel paint is frequently used on plasters, concrete, woods, metals etc. There are different types of enamel paint available to serve different purpose but generally 'Floor Enamel' paint is used in case of plaster, concrete, stairs, basements, porches, patios etc. Basically, enamel paint consists of dehydrated castor oil, titanium dioxide, colophony resin ester, anti-oxidants, clay, zinc oxide, proprietary complex driers etc. (Madankar et al., 2011; Kumar, 2015). Generally, enamel paints are applied with oil or water on the surface. A unique advantage of enamel paint is its ability to dry quickly when exposed to air. The final results are a lot smoother and almost near perfect finish with little sheen, depending on the oil content. Although oil-based enamel paint takes little bit higher time about eight to twelve hours to dry, it ends up with a harder finish. Once hardened, enamel paint can last for many years. It is resistant to mildew and can be washed if it gets stained. Moreover, the paint coating can resist the effect of high temperature on the material surface up to a certain temperature. At higher temperature certain physical changes on the coating can be noticed more specifically the change in colours of the material. The gradual changes of colour can be identified using several parameters. The 'CIELAB' colour space is one of them. It expresses colour as three values and those are $L^{*}$ for the lightness from black (0) to white $(100), a^{*}$ from green $(-)$ to red $(+)$, and $b^{*}$ from blue $(-)$ to yellow $(+)$. CIELAB was designed so that the same amount of numerical change in these values corresponds to roughly the same amount of visually perceived change (Raljic et al., 2008; Sinaga, 2019). At the higher working temperature, the surface of the paint dries to boot rapidly and build up bumps, blisters and other imperfections, such as lifting and cracking. Under high heating situation, enough data are not available about building paints. 
In the present paper, the prediction of thermal degradation of enamel paint coating over cement plaster is investigated using simple optical images, microstructures and thickness of the samples. The thermal degradation is predicted by detecting the change of colour of the composite samples subjected to isochronal heating at temperatures ranging from $25^{\circ} \mathrm{C}$ (room temperature) to $350^{\circ} \mathrm{C}$ for a period of one hour. The potential of the method is then verified through the visual colour change as well as microstructures of the samples.

\section{METHODOLOGY AND EXPERIMENTAL PROGRAM}

Cement and sand are mixed into 1:3 ratios to produce the plaster samples. The dimension of plaster sample is 50 $\mathrm{mm} \times 50 \mathrm{~mm}$ x $50 \mathrm{~mm}$ and six samples of same dimension are taken. All the samples are painted with synthetic white enamel paint on one particular surface. This type of enamel paint consists of white lead and zinc white as the base, resins as binder, white spirit as the solvent or thinner, fine powder of mineral as colouring pigment and lead, zirconium, copper, cobalt as additives. Following the painting samples is kept one day for drying. After drying the plaster samples are heated isochronally. Heat treatment of the plaster samples is done in an electric furnace. Heating is applied at different temperatures ranging from room temperature $\left(25^{\circ} \mathrm{C}\right)$ to $350^{\circ} \mathrm{C}$ for one hour. After being cooled, samples are tested for various physical and optical properties.

The images of the heated samples are taken with Canon EOS 750D model DSLR camera for examine the visual changes. The optical micrographs of the samples are also taken with Mighty Scope 5M USB digital microscope for grain size analysis. The images of the samples are analysed through MATLAB R2017a earlier versions software for determining the tristimulus colour parameter $\mathrm{L}^{*}, \mathrm{a}^{*}, \mathrm{~b}^{*}$ and $\mathrm{E}^{*}$ values. These parameters provide the complete numerical values of the colour. Where $\mathrm{L}^{*}$ represents lightness, $\mathrm{a}^{*}$ represents rednessgreenness and $b^{*}$ represents yellowness-blueness of the colour. Total colour difference $\mathrm{E}^{*}$ is calculated based on the variation of $\mathrm{L}^{*}, \mathrm{a}^{*}, \mathrm{~b}^{*}$ values (Hunter and Harold, 1987). The RGB colour model also considered in which red, green, and blue light are added mutually to replicate a collection of colours (Robert, 2004). The changes of these values with respect to temperature changes are shown graphically. The Arbitrary Unit, AU is used for all the cases. The changes in proportion of the basic colour red, green and blue with respect to temperature changes are also shown graphically. Figure 1 gives an idea about the setup of the experiment carried out for this study. A vernier calliper was used to measure the thickness of enamel paint layer heated at different temperature. A without painting plaster sample also heated simultaneously to measure the change of the thickness of the sample under heating at different temperatures. These values are considered to calculation of real deviation of thickness of the paint layers.

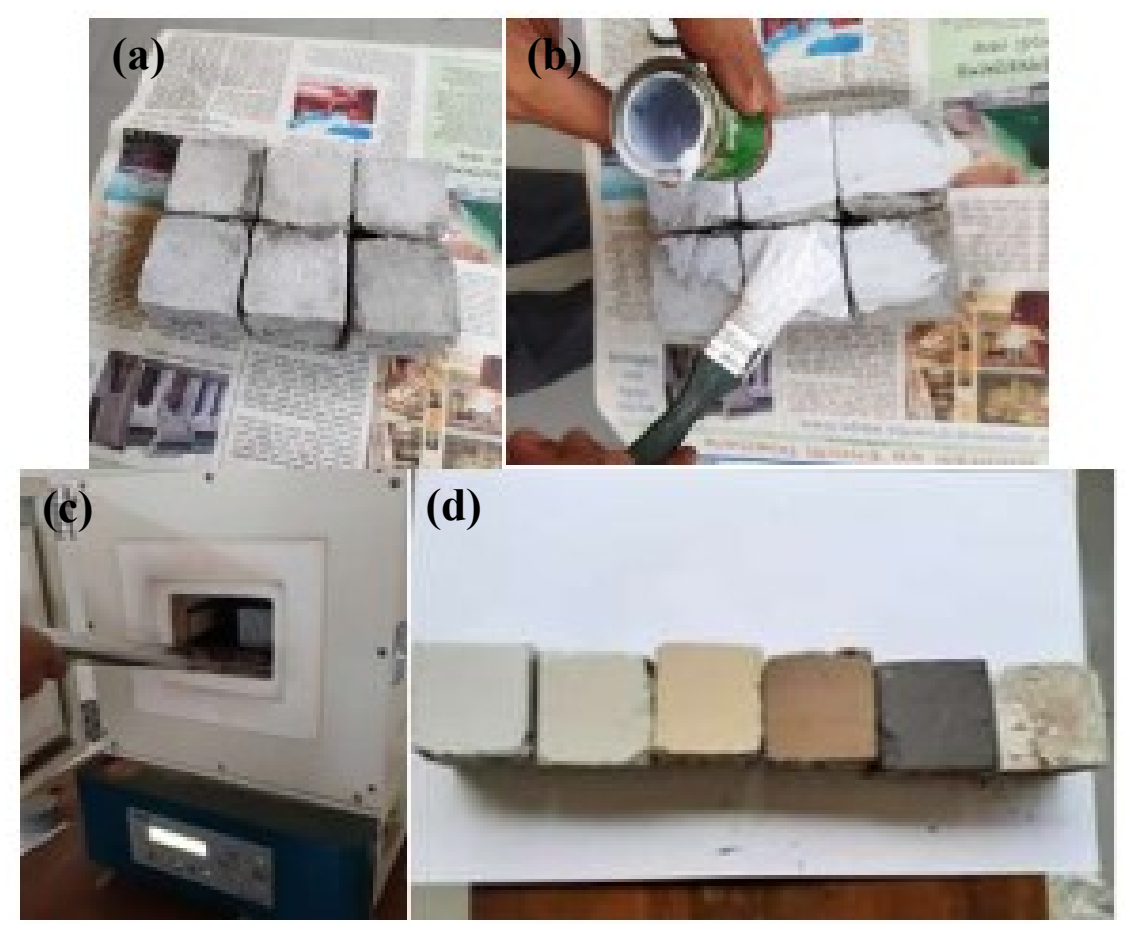

Figure 1: Experimental setup (a) plaster samples (b) enamel painting (c) electrical furnace and (d) heated samples 


\section{RESULTS AND DISCUSSION}

\subsection{Optical Observations}

In an attempt to predict the thermal degradation of the plaster samples, all six specimens were isochronally heated at different temperatures for one hour and the corresponding optical images were recorded, which are shown in Figure 2. The images show that, with the increase of heating temperature, the samples are thermally affected. But up to $100^{\circ} \mathrm{C}$ no significant change is found. After $100^{\circ} \mathrm{C}$ the colour change is noticeable and it is because of the evaporation of water molecules from the paint. After $200^{\circ} \mathrm{C}$ the colour has changed drastically because of the chemical change of paint ingredients (Berg et al., 1999). Finally, at $350^{\circ} \mathrm{C}$ the sample got burned and the paint layer came out from the plaster.

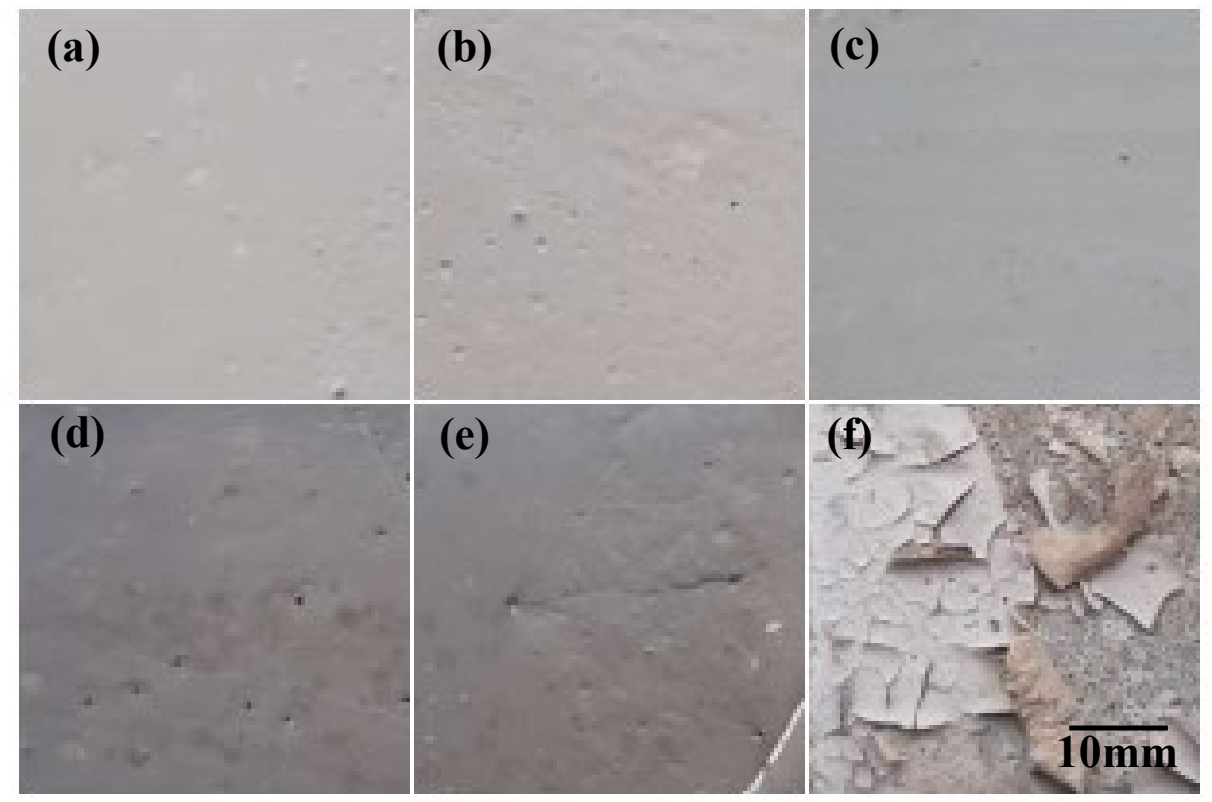

Figure 2: Change of colour of different plaster samples after heating at different temperatures for one hour (a) $25^{\circ} \mathrm{C}$ (b) $100^{\circ} \mathrm{C}$, c) $200^{\circ} \mathrm{C}$, (d) $250^{\circ} \mathrm{C}$, (e) $300^{\circ}$ and (f) $350^{\circ} \mathrm{C}$

\subsection{Optical Microscopy}

The microstructures of the samples are taken for grain analysis which is shown in Figure 3 . The change in grain sizes also remains insignificant up to $100^{\circ} \mathrm{C}$. Because of the evaporation of water molecules, the grain size

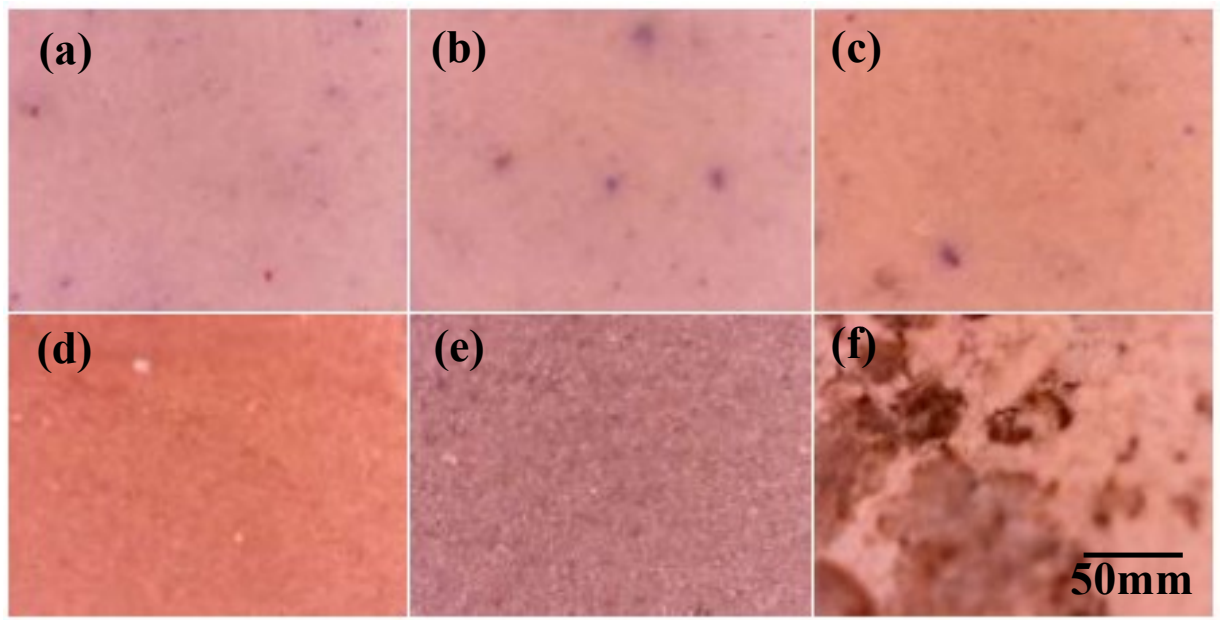

Figure 3: Optical micrograph of colour of different plaster samples isochronal heating at different temperatures for one hour (a) $25^{\circ} \mathrm{C}$, ( b) $100^{\circ} \mathrm{C}$, (c) $200^{\circ} \mathrm{C}$, (d) $250^{\circ} \mathrm{C}$, (e) $300^{\circ} \mathrm{C}$ and (f) $350^{\circ} \mathrm{C}$ 
becomes thicker after $100^{\circ} \mathrm{C}$ and changes drastically after $200^{\circ} \mathrm{C}$ due to the chemical change of carbonaceous materials of paint (Erhardt, et al., 2005). At $350^{\circ} \mathrm{C}$ the microstructure defines total burning structure of the coating layer.

\subsection{Change of Tristimulus Colour and Thickness Parameter}

The colour changes of the samples are examined by tristimulus colour parameter ' $L^{*}$ ', ' $a$ ' ' and ' $b$ *' values. The graphical representations of change of these values are shown in Figure 4. The ' $L^{*}$ ' value vs heating temperature graph shows that up to $200^{\circ} \mathrm{C}$ there is a small decrease in ' $\mathrm{L}^{*}$ ' value. After $200^{\circ} \mathrm{C}$ the value starts to decrease greatly up to $250^{\circ} \mathrm{C}$ and then shows a slight increase from $250^{\circ} \mathrm{C}$ to $300^{\circ} \mathrm{C}$. The ' $\mathrm{a} *$ ' value vs heating temperature graph indicates the increase of ' $\mathrm{a}^{*}$ ' value up to $100^{\circ} \mathrm{C}$ and then a significant decrease up to $200^{\circ} \mathrm{C}$ and then again shows an increase with a large slope till $250^{\circ} \mathrm{C}$ and finally with a smaller slope till $300^{\circ} \mathrm{C}$. The change of ' $\mathrm{b}$ *' value remains insignificant until $100^{\circ} \mathrm{C}$ and then shows a decreasing behaviour up to $250^{\circ} \mathrm{C}$ and finally increases from $250^{\circ} \mathrm{C}$ to $300^{\circ} \mathrm{C}$ range before the samples got burned. It seems to be increase in darkness by the heating effect. The combined effect of colour difference $\mathrm{E}^{*}$ confirms that the rate is low at heating up to $200^{\circ} \mathrm{C}$ and drastically changed the rate beyond this temperature. It is occurred due to evaporation of water, vaporisation of chemicals and finally chemical changes of the enamel paint layer through cross linking decomposition and imides bonds (Gornicka and Gorecki, 2010).
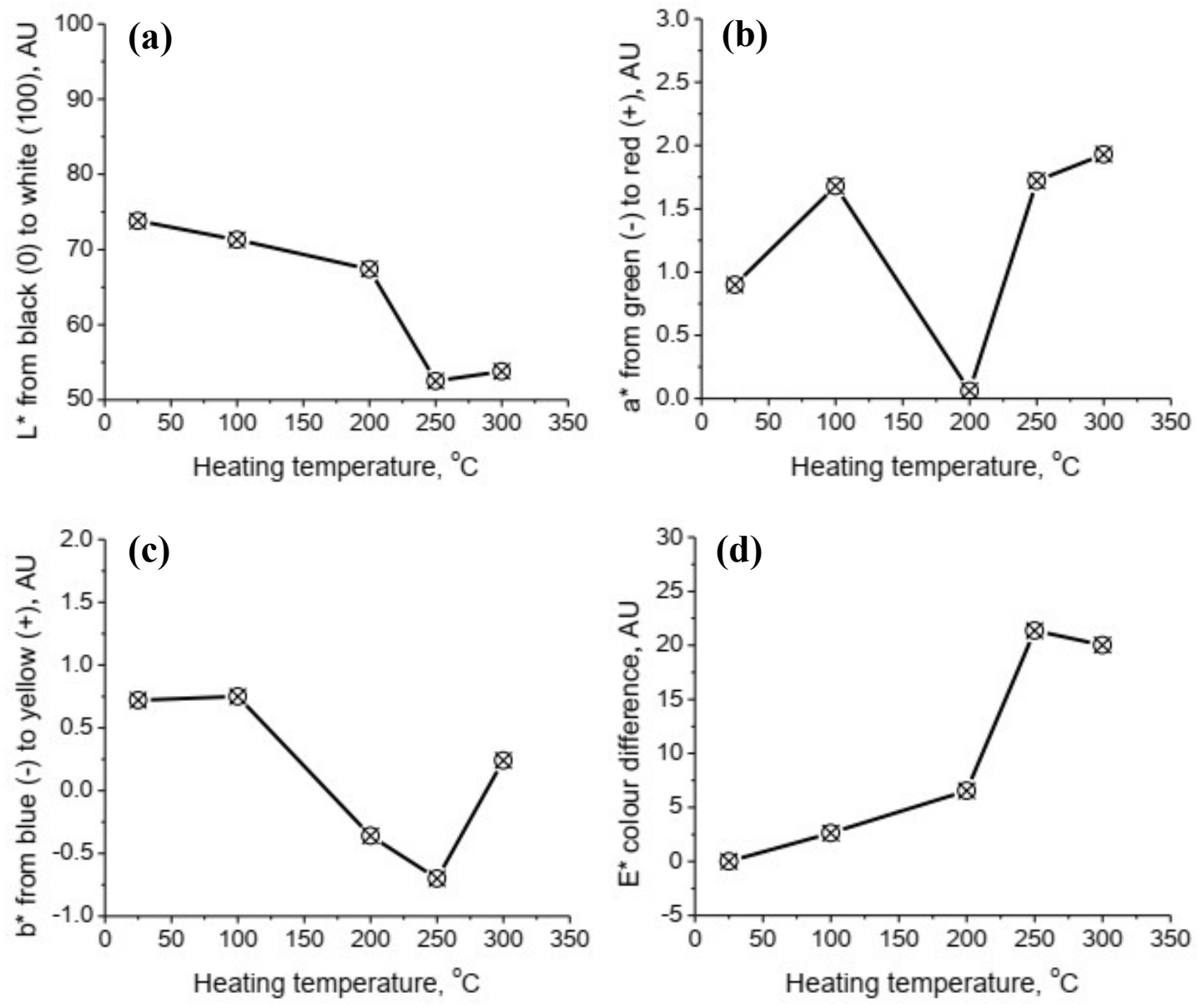

Figure 4: Change of colour of plaster samples after heating at different temperatures for one hours (a) $L^{*}$ (b) a* (c) b* and (d) E*

The proportion of three basic colours (Red, Green and Blue) along with the thickness of enamel paint coating respect to temperature changes are shown graphically in Figure 5. The red colour proportion shows a decreasing trend with a smaller slope up to $200^{\circ} \mathrm{C}$ and then decreases drastically till $250^{\circ} \mathrm{C}$. Finally, it shows a slight increasing trend from $250^{\circ} \mathrm{C}$ to $300^{\circ} \mathrm{C}$ before getting burned. Similarly, the Blue and Green colour proportion also show almost the same pattern. It happens because when the samples are heated the proportion of black colour (black colour indicates the absence of other colours) increases as the samples tend to be burned. Thus, the proportions of all three colours begin to decrease (Bentley and Turner, 1998). The influence of isochronal 
heating on the thickness of enamel coating shows the small declining values bellow the temperature around at $200^{\circ} \mathrm{C}$ however thickness loss as the maximum temperature increased. At low temperature around $100^{\circ} \mathrm{C}$ the change is low because low water vapour is released as it is oil based paint. It accelerates after this temperature. Up to these temperatures chemical bonds begin to slash and thermal degradation starts and makes the paint layer brittle and finally burned.
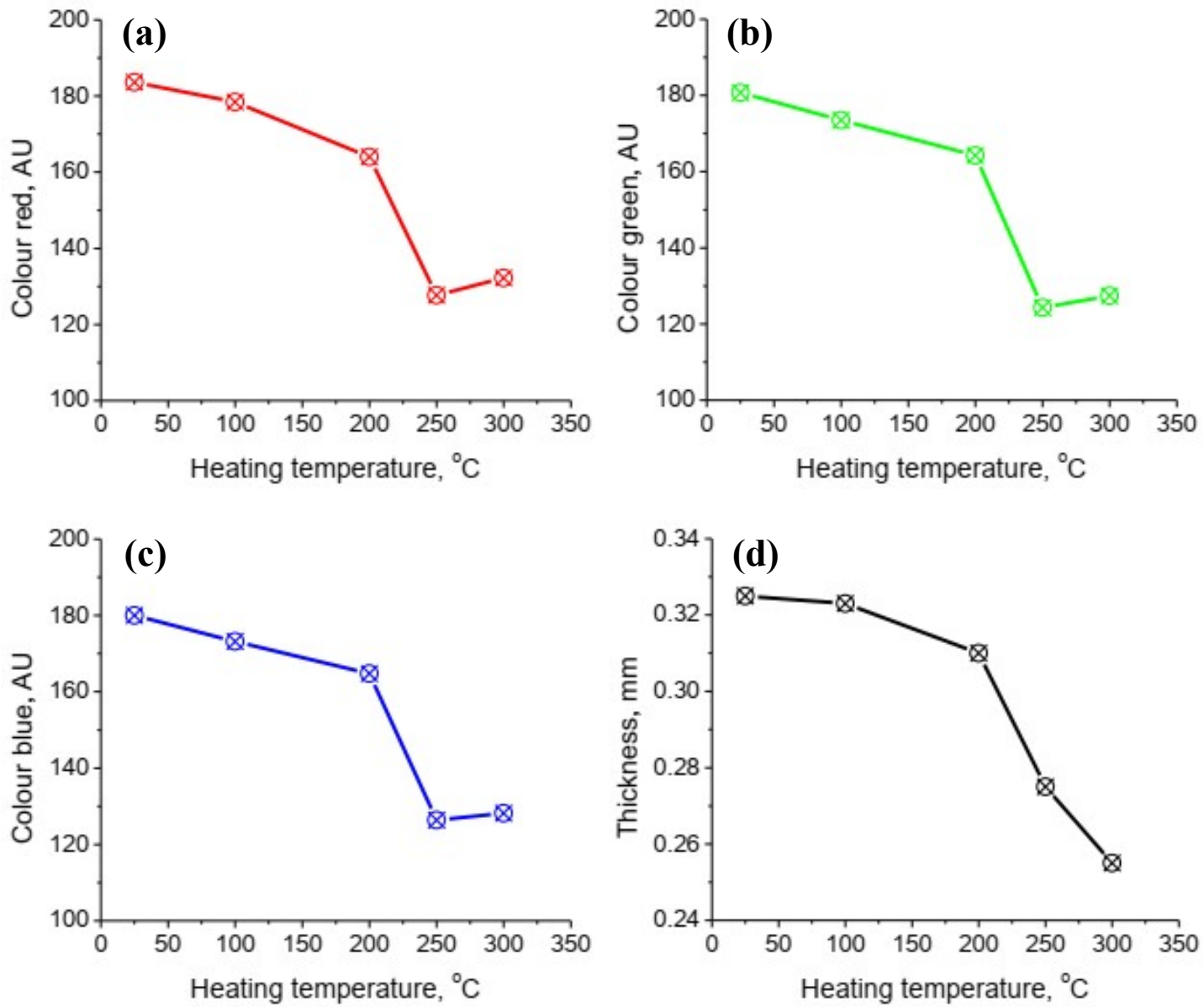

Figure 5: Change of RGB colour of plaster samples after heating at different temperatures for one hours (a) Red (b) Green (c) Blue and (d) the thickness of enamel paint coating.

\section{CONCLUSIONS}

The potential of a simplified visual inspection method is investigated to predict the thermal degradation of the enamel paint layer on plaster samples. More specifically, the degradation is predicted based on the change in colour of the optical images of the samples taken after every thermal treatment performed at a certain interval of temperature. No significant change in colour of the images is observed up to the heating performed at $100^{\circ} \mathrm{C}$. It is because only after $100^{\circ} \mathrm{C}$ the water molecules from the painted surface begin to evaporate. After $200^{\circ} \mathrm{C}$ the changes become more noticeable as the carbonaceous materials of paint start to be changed chemically. The painted plaster samples are found to be completely burnt out after the heating at $350^{\circ} \mathrm{C}$, which is, however, well reflected by the corresponding colour of the sample images. The microstructure analysis also shows the coarsening of grains with increasing temperatures. Finally, the variation of tristimulus colour parameters indicates the effect of significant increase of darkness after heating beyond $200^{\circ} \mathrm{C}$. The proportion of combination of three basic colours (RGB) also decreases with increasing temperatures and thus it is very much co-relational with the visual examinations. The thickness of the enamel paint layer drastically falls beyond the temperature at $200^{\circ} \mathrm{C}$ by act in accordance with the degradation of colour. 


\section{ACKNOWLEDGEMENTS}

This is the extended version of the conference paper presented in ICCESD 2020. Thanks to DAERS office Bangladesh University of Engineering and Technology, Dhaka-1000, for providing the laboratory facilities. We acknowledge the two anonymous reviewers and Editor of Journal of Engineering Science for their support in the publication process.

\section{REFERENCES}

Bentley, J. and Turner, G. P. A., 1998. Introduction to paint chemistry and principles of paint technology, 4th edition, Chapman and Hall, UK.

Berg J. D. J., Berg, K. J. and Boon J. J. 1999. Chemical changes in curing and ageing oil paints, In: 12th Triennial Meeting Lyon 29 August - 3 September, Science Park, Amsterdam, The Netherlands.

Erhardt, D., Tumosa, C. and Mecklenburg, M., 2005. Long-Term Chemical and Physical Processes in Oil Paint Films, Studies in Conservation, 50(2), 143-150.

Gornicka, B., Gorecki, L., 2010. TGA/DTG/DSC investigation of thermal ageing effects on polyamide-imide enamel, Journal of Thermal Analysis and Calorimetry, 101, 647-650.

Hunter, R. S. and Harold, R. W., 1987. The Measurement of Appearance, 2nd edition, John Wiley and Sons, Inc. New York, USA.

Kumar, S. S., 2015. Development of Industrial Automotive Paint with Natural Raw Material Castor Oil as a Substitute of Polymeric Plasticizer, International Journal of Engineering and Applied Sciences, 2(12), 141-145.

Lambourne, R and Strivens, T. A., 1999. Paint and surface coatings: Theory and practice, 2nd edition, published by Woodhead Publishing Ltd, Abington Hall, Abington, Cambridge CB1 6AH, England.

Madankar, C. S., Karadbhajne, V. Y., Waykar, N. G. and Walhekar, A. G., 2011. Synthesis of Enamel Paint based on Novel Rosinated Maleinized Castor Oil using Zinc Oxide as a Natural Drier, International Journal of ChemTech Research, 3(1), 391-397.

Piper, R., 1965. The hazards of painting and varnishing, British Journal of Industrial Medicine, 22, 247-260

Raljic, J. V. P., Lakic, N. S., Petronijevic, J. G. L., Barac, M.B., and Sikimic, V. M, 2008. Color Changes of UHT Milk During Storage, Sensors (Basel), 8(9), 5961-5974.

Robert H., 2004. Exploring Colour Photography: A Complete Guide. Laurence King Publishing. London, UK.

Sinaga, A. S. R. M., 2019. Color-based Segmentation of Batik Using the L*a*b Color Space, SinkrOn, 3(2), 175-179.

(C) 2021 the Authors. Journal of Engineering Science published by Faculty of Civil Engineering, Khulna University of Engineering \& Technology. This is an open access article under the terms of the Creative Commons AttributionNonCommercial-NoDerivatives License, which permits use and distribution in any medium, provided the original work is properly cited, the use is non-commercial and no Modifications or adaptations are made. 